\title{
Regional Differences in Technology Gap Ratio and Efficiency in African Agriculture: A Stochastic Metafrontier Analysis
}

\author{
Abraham Amoussouga Gero ${ }^{1,2}$ \\ ${ }^{1}$ Department of Agribusiness and Agricultural Policies, National University of Agriculture, Porto-Novo, Benin \\ ${ }^{2}$ Laboratory of Financial Development and Finance Research, University of Abomey-Calavi, Abomey-Calavi, Benin
}

\section{Email address:}

gerolandry@hotmail.fr

\section{To cite this article:}

Abraham Amoussouga Gero. Regional Differences in Technology Gap Ratio and Efficiency in African Agriculture: A Stochastic Metafrontier Analysis. International Journal of Agricultural Economics. Vol. 5, No. 3, 2020, pp. 80-88. doi: 10.11648/j.ijae.20200503.14

Received: May 26, 2020; Accepted: June 9, 2020; Published: June 20, 2020

\begin{abstract}
Agriculture plays an important role in the African continent's growth. However, regions' characteristics differences explain different types of production technologies use leading to a technological gap which delays these regions' economic convergence. This article uses the stochastic metafrontier analysis based on a new approach for Technical Efficiency's (TE) estimation and the technological gap ratios (TGR) of the agricultural production of the five African regions from 1980 to 2012 . The results reveal a very high average TE score of $92.73 \%$ of the five regions whereas a low TGR score of $35.63 \%$ is noticed. The EAST region is the closest one to the best technology available with a $68.73 \%$ score. Besides, these results also show the existence of a catch-up phenomenon between low TGR level countries and those with higher TGR level. Zimbabwe has the highest catch-up score with a yearly average of 3\%. Considering the agricultural sector's importance in Africa's national production, the results suggest increasing investments in Research and Development, popularizing services, and a policy of larger expansion of the technologies applied by the regions close to the optimal technology in order to facilitate new agricultural production techniques' adoption and development. Agriculture plays an important role in the growth of the African continent. However, regions diversity of characteristics explains the use of different types of production technologies, resulting in a technology gap that delays the economic convergence of these regions.
\end{abstract}

Keywords: Metafrontier, Technical Efficiency, Technological gap, Agricultural, Africa

\section{Introduction}

Adopting technologies and using improved agricultural practices are considered as the main factors responsible of agricultural productivity differences between countries and regions $[1,2]$. Recent technologies' adoption determines in fact productivity level reflecting the technological sophistication degree responsible of the gap's level between countries [3]. As a matter of fact, measuring the technical efficiency and the agricultural technological gap existing between regions remains an important topic at the international level. Technological Gap Ratio (TGR) is defined as the variation of technical efficiency (TE) between countries and regions measuring the relation between a maximal production and a real production for given inputs.

The traditional production theory points out that producers from different regions or countries face variable production possibilities for they have to choose among different types of input-output combinations considered as different set of technologies $[4,5]$. These technological sets vary due to human and physical capital stock, resources donations, infrastructures and each region or country's economic structure. Likewise, according to differences in technological capacities, innovation favors technologies heterogeneity among firms [6]. As a matter of fact, a technological gap existence between regions makes inaccurate production frontiers comparison between them for every region has its own technology. In other words, not taking into account the existing technological heterogeneity between regions leads to a wrong technical efficiency's estimation and awards technological gaps to technical inefficiency. To correct this bias, Hayami and Ruttan [7] have introduced the metafrontier 
concept which takes into account technological gap and helps compare many firms' located among different groups' technical efficiency such as industries, countries or regions. Moreover, Binswanger and Ruttan [8] highlight that the production metafrontier framework does not imply that all producers operate on the universal production function but rather on the enveloping figure of the most efficient producers' production levels. Later on, Battese and Rao [9] have introduced an approach of stochastic frontier to estimate TE of producers in different groups production metafrontier. O'Donnell and al. and Battese and al. [5, 10] have modified this approach by introducing a mixed procedure composed of two steps. The first step is based on the stochastic frontier analysis (SFA) to estimate each group's technical efficiency and the second one relies on the linear programming for the metafrontier's estimation. However, the second step comes out with some difficulties. On one hand, no static property can be obtained from the metafrontier estimated parameter, and on the other hand, the results and the idiosyncratic shocks were at random [11]. So, to solve these difficulties, Huang and al. [12] have introduced a new procedure subdivided into two steps using the SFA to estimate groups' frontiers and the metafrontier.

On the empirical level, many researches based on the production metafrontier have been dedicated to regions of the world and to specific production groups in order to measure the technological gap level and the impact of common and national agricultural policies through the introduction of new production technologies. Khanal and al. [13] studying the agricultural production in relation with agroecologic regions in Nepal notice that there are efficiency gains in the production technology and that agroecologic regions do not share the same production technology. Villano and al. [14] comparing rice producers' technical efficiency in Philippines between those using certified seeds and those not doing so, notice that certified seeds users have a technological gap ratio (TGR) score superior to non-users. Moreira and al. [15] analyzing some South American countries milk productions notice some very high TGR scores meaning that the technological gap between countries is low. Liu and al. [16] who studied main agricultural producers' technical efficiency from 1961 to 2013 in Asia observe high TGR heterogeinity levels and that China and India are the closest countries to the metafrontier. O'Donnell and al. and Huanng and al. $[5,12]$ studying the world regions agricultural performances with different approaches have noticed that the average TGR level was respectively of $72.7 \%$ and $81.4 \%$ on one hand; and that Africa was classified among the closest regions to the production metafrontier. This region's agricultural producers have some advantages in using their agricultural technologies compared to the others. Nkamleu and al. [17] likewise, in examining agricultural productivity in Africa, notice that technological gap plays an important role in a region's capacity at challenging another one and that the East African region was the closest one to the production metafrontier.

In the African region, agricultural productivity growth leads to a rising national production for this sector is at an important position in the production and contributes to economic growth. More precisely, agriculture represents in average on the last five years around $22 \%$ of the GDP and hires nearly $53 \%$ of the active population [18]. The role played by agriculture on the African's development process has led to multiple regional policies such as the Agriculture Detailed Development Program (CAADP) in 2003 and the adoption of the West African States Economic Community Agricultural Policy (ECOWAP). These programs' common objective is to stimulate productivity and agricultural competitiveness. However, most agricultural productions remain characterized by familial exploitation types with an extremely reduced level, low incomes, a strong sensitivity to climate clashes and a strong disparity in natural resources dotation. These insufficiencies are a hindrance to the settlement of the African Continental Free Exchange Zone (AfCFTA) the success of which will depend on the comparative advantage in the production technology or in the technological gap existing between countries in order to accelerate commerce between regions. As a matter of fact, it becomes necessary to assess the existing technological gap between countries and to determine whether these gaps notice some reductions in the time.

This research objective is to analyze technological differences between the African regions. More specifically, it will be about i) determining frontiers and the metafrontier specific to each region; ii) assessing the level of technological gap between regions iii) measuring the progress of the reduction of technological gaps. Our study contributes to existing literature in the following way. In a first time, we apply production metafrontier with Huang and al. [12] new procedure contrarily to the data enveloping approach used by Nkamleu and al. [17] which does not take random noise into account. Secondly, this article contrarily to researches made on Africa, uses tests of model specifications which allows stronger results' obtaining for economical policies' involvement in agricultural technical efficiency. In a third time this article will help test the technological gap catch-up hypothesis between countries with a low level of technology and the ones with a high one.

The rest of the paper is organized as it follows. Section 2 presents the methodology as well as the data used and the empirical model. Section 3 highlights the empirical results and the discussion. And finally, section 4 presents the conclusion and the economical polices' involvement.

\section{Methodology}

In this section, we will present in two steps the stochastic metafrontier approach (SMF) procedure and the empirical model specification from the likelihood ratio tests (LR).

\subsection{Stochastic Metafrontier Model}

According to the procedure, the first step consists in estimating the frontiers specific to each group whereas the second one uses the SFA approach to estimate production metafrontier. The production metafrontier specific to every 
African region is presented in the following way

$$
Y_{j i t}=f_{t}^{j}\left(X_{j i t}\right) e^{V_{j i t}-U_{j i t}}, j=1,2, \ldots, J ; i=1,2, \ldots, N ; t=1,2, \ldots, \mathrm{T}
$$

where $Y_{j i t}$ and $X_{j i t}$ designate respectively inputs and outputs production vectors of $i$ countries agricultural production in $j$ region at $t$ period. In accordance with the stochastic frontiers standard, $V_{j i t}$ measures random errors determining the statistical noise and $U_{j i t}$ represent non negative random errors representing TE. We suppose that $V_{j i t}$ are distributed independently and identically as $N\left(0, \sigma_{v}^{j 2}\right)$; $U_{j i t}$ are also independent and follow a truncated distribution like $N\left(\mu, \sigma^{2}\right)$. The regression model is estimated by the maximum likelihood and countries TE is defined by:

$$
T E_{i t}^{j}=\frac{Y_{j i t}}{f_{t}^{j}\left(X_{j i t}\right) e^{V_{j i t}}}=e^{-U_{j i t}}
$$

The production metafrontier common to all groups at the $\mathrm{t}$ period is defined by $f_{t}^{M}\left(X_{j i t}\right), j=1,2, \ldots, J$. By definition, the relationship between the metafrontier $f_{t}^{M}\left(X_{j i t}\right)$ and each group $f_{t}^{j}\left(X_{j i t}\right)$ frontier is:

$$
f_{t}^{j}\left(X_{j i t}\right)=f_{t}^{M}\left(X_{j i t}\right) e^{-U_{j i t}^{M}}, \forall j, i, t
$$

where $U_{j i t}^{M} \geq 0$, which implies that $f_{t}^{M}(.) \geq f_{t}^{j}($.$) and the$ ratio's expression in the $j$ region and the metafrontier production is defined by the technological gap ratio (TGR):

$$
T G R_{i t}^{j}=\frac{f_{t}^{j}\left(x_{j i t}\right)}{f_{t}^{M}\left(X_{j i t}\right)}=e^{-U_{j i t}^{M}} \leq 1
$$

A TGR value equalling the unit implies that the country has used the most advanced technology. So, no matter the $X_{j i t}$, level, the observed $Y_{j i t}$ production and the production metafrontier $f_{t}^{M}\left(X_{j i t}\right)$ can be decomposed in the following way:

$$
\frac{Y_{j i t}}{f_{t}^{M}\left(X_{j i t}\right)}=T G R_{i t}^{j} \times T E_{i t}^{j} \times e^{V_{j i t}}
$$

As the random noise component is obtained from the production stochastic frontiers estimation, the equation can be written as it follows:

$$
T E_{j i t}^{*}=\frac{Y_{j i t}}{f_{t}^{M}\left(X_{j i t}\right) e^{V_{j i t}}}=T G R_{i t}^{j} \times T E_{i t}^{j}
$$

with $T E_{j i t}^{*}$ representing technical efficiency obtained through the production metafrontier. The method proposed by Huang and al. [12] in the second step using the stochastic frontier regression rather than the mathematical programming in the metafrontier estimation, it specifically take into account $\hat{f}_{t}^{j}\left(X_{j i t}\right)$ estimation error in $f_{t}^{j}\left(X_{j i t}\right)$ estimation. The estimation according to the SFA of the frontier specific to each region is:

$$
\begin{aligned}
& \ln \hat{f}_{t}^{j}\left(X_{j i t}\right)-\ln f_{t}^{j}\left(X_{j i t}\right)=e_{j i t}-\hat{e}_{j i t} \\
& \ln Y_{i t}=\beta_{0}+\sum_{k=1}^{5} \beta_{k} \ln X_{k i t}+\frac{1}{2} \sum_{k=1}^{5} \sum_{h=1}^{5} \beta_{k h} \ln X_{k i t} \ln X_{h i t}+\beta_{t} T+\frac{1}{2} \beta_{t t} T^{2} ;+\sum_{k=1}^{5} \beta_{k t} \ln X_{k i t} T+V_{i t}-U_{i t}
\end{aligned}
$$

In making $V_{j i t}^{M}=e_{j i t}-\hat{e}_{j i t}$, the equation (7) can be written:

$$
\ln \hat{f}_{t}^{j}\left(X_{j i t}\right)=\ln f_{t}^{M}\left(X_{j i t}\right)-U_{j i t}^{M}+V_{j i t}^{M}
$$

with $V_{j i t}^{M}$ being the statistical noise representing the gap between $\hat{f}_{t}^{j}\left(X_{j i t}\right)$ and $f_{t}^{M}\left(X_{j i t}\right)$.

Equation (8) looks like the SFA classical regression and is called the stochastic metafrontier (SMF), in which the technology $U_{j i t}^{M} \geq 0$ is supposed to follow a truncated normal distribution $U_{j i t}^{M} \sim N^{+}\left(\mu^{M}, \sigma_{\mu}^{M 2}\right)$ and is independent from $V_{j i t}^{M}$. The new procedure allows to show that the frontier specific to the group is superior or equal to the metafrontier due to $V_{j i t}^{M}$ error in equation (8). However, the metafrontier is still superior to the real specific group frontier $\ln f_{t}^{M}\left(X_{j i t}\right) \geq$ $\ln \hat{f}_{t}^{j}\left(X_{j i t}\right)$. The estimated TGR is calculated by the following formula:

$$
\widehat{T G R}_{t}^{j}=\hat{E}\left(e^{-U_{j i t}^{M}} \mid \hat{\varepsilon}_{j i t}^{M}\right) \leq 1
$$

Where $\quad \hat{\varepsilon}_{j i t}^{M}=\ln \hat{f}_{t}^{j}\left(X_{j i t}\right)-\ln \hat{f}_{t}^{M}\left(X_{j i t}\right) \quad$ represents the residuals of equation (8). $T E^{*}$ corresponding estimation is equal to individual countries TGR and TE estimation product:

$$
\widehat{T E}_{J \imath t}^{*}=\widehat{T G R}_{i t}^{j} \times \widehat{T E}_{i t}^{j}
$$

\subsection{Data and the Empirical Model}

We use a set of panelled data built for 33 African countries for the period going from 1980 to 2012 given by the Statistics of Food and Agriculture Organization of the United Nations [19]. These countries are divided into five regions Central, East, Mena (Middle East and North Africa), Southern, West. Data used for this analysis contain one output variable and five input variables. The agricultural production $\left(Y_{j i t}\right)$ is expressed as the net added value of the agricultural production in "international million dollars" on 2004-2006 period, fertilizers $\left(X_{1 j i t}\right)$ representing the addition of used input, livestock $\left(X_{2 j i t}\right)$ used as proxy of land pasture and measured in terms of number of animal, the agricultural workforce $\left(X_{3 j i t}\right)$ defined as the number of economically active people in the agricultural production, the net capital stock $\left(X_{4 j i t}\right)$ expressed in international million dollars at a constant price of the basic year of 2005 with the extrapolation method use for the period going from 2008 to 2012, and the land $\left(X_{5 j i t}\right)$ represented by the addition of all arable lands and the surface used for permanent cultivations. In this application, a stochastic frontier model with inefficient variables effects in the time proposed by Battese and Coelli [20] is used. So, the flexible translog stochastic production function representing every regions agricultural production used is: 
where $T$ is a yearly artificial variable representing the production functions variation in time and $\beta$ a parameter vector to be estimated. $V_{i t}$ is supposed to be distributed in an independent and identical way as a random $N\left(0, \sigma_{v}^{2}\right)$ error term. $U_{i t}$ is a random variable supposed to follow a truncated distribution in an independent and identical way, associated with technical efficiency $N\left(\mu, \sigma_{u}^{2}\right)$.

Table 1. Specification test for model selection.

\begin{tabular}{|c|c|c|c|c|c|c|}
\hline \multirow{2}{*}{ Null hypothesis } & \multicolumn{6}{|c|}{ Test de likelihood Ratio } \\
\hline & Central & East & Southern & West & Mena & Metafrontier \\
\hline Cobb Douglas model & $614.70 * * *$ & $38.60 * * *$ & $266.04 * * *$ & $1634.11 * * *$ & $752.17 * * *$ & -89.20 \\
\hline No technical inefficiency & $11.41 * *$ & -9.02 & $58.13 * * *$ & $75.74 *$ & -41.98 & $730.69 * * *$ \\
\hline Time invariant model & 0.54 & -14.3 & $64.83 * * *$ & -5.48 & $52.4 * * *$ & $76.1 * *$ \\
\hline Stochastic & 0.04 & 0.79 & $17.41 * * *$ & 2.36 & $52.6 * * *$ & $220.70 * * *$ \\
\hline Half normal distribution & -0.01 & -16.24 & 0.83 & -0.54 & $52.62 * * *$ & $14.9 * * *$ \\
\hline Homogenous technology across regions & \multicolumn{6}{|l|}{$861.5268 * * *$} \\
\hline
\end{tabular}

$* * *, * *$ and $*$ denote $1 \%, 5 \%$ and $10 \%$ level of statistical significance.

Table 1 above represents the different model specification tests. The appropriate functional form of the production function must be selected from a given number of tests based on the general realistic ratio (LR). The LR tests statistics which has an approximate distribution equalling the number of parameters supposed to be zero in the nil hypothesis. For the production functions specification form, the hypothesis stating that the Cobb-Douglas specification rather than translog represents adequately the data has been rejected for all models except the metafrontier model. The hypothesis supposing that technical inefficiency effects are not present is rejected for all regions except the East and Mena regions, meaning that technical inefficiency is not evident for these regions considering their level of technology [21]. The hypotheses according to which time changing model with a stochastic production frontier is applied are rejected for all regions except for the Central and East regions. The hypothesis supposing a semi-normal distribution is accepted for all regions except for the Mena region and the metafrontier. The hypothesis stating that regional stochastic frontier models are the same is rejected. This suggests that it would be logic to estimate countries technical efficiency in relation to a metafrontier production function.

\section{Results and Discussions}

Table 2. Estimation of parameters of region frontiers and metafrontier.

\begin{tabular}{|c|c|c|c|c|c|c|}
\hline Variables & Central & Southern & West & East & Mena & Metafrontier \\
\hline Ln (fertiliser) & 0.164 & -0.542 & -0.432 & $-0.989^{*}$ & -0.0931 & $0.0411 * * *$ \\
\hline Ln (livestock) & -2.555 & 2.859 & $10.17 * * *$ & 0.624 & 16.31 & $0.0677 * * *$ \\
\hline Ln (labor) & $3.006^{*}$ & 2.458 & $22.16^{* * *}$ & $-18.35 * * *$ & -0.529 & $0.0664 * * *$ \\
\hline Ln (capital) & 3.695 & $-8.738 * * *$ & $-28.62 * * *$ & $-8.933 *$ & -9.105 & $0.401 * * *$ \\
\hline Ln (land) & $-6.216^{* *}$ & 2.668 & $7.312^{* * *}$ & $26.44 * * *$ & 11.60 & $0.393 * * *$ \\
\hline Time & 0.0239 & 0.0277 & $-0.183 * * *$ & 0.142 & -0.159 & $0.00848 * * *$ \\
\hline $\operatorname{Ln}(\text { fertiliser })^{2}$ & 0.00340 & $0.0189 *$ & 0.00855 & $0.0385 * *$ & -0.0253 & \\
\hline $\operatorname{Ln}(\text { labor) })^{2}$ & $-0.791 * * *$ & -0.0832 & $-1.791 * * *$ & $2.276 * *$ & 0.498 & \\
\hline Ln $(\text { capital })^{2}$ & -0.781 & 0.224 & $-4.375 * * *$ & $-3.681 *$ & 2.197 & \\
\hline Ln (land) ${ }^{2}$ & -0.741 & 0.0583 & $-1.462 * * *$ & 3.311 & -1.230 & \\
\hline Time $^{2}$ & $0.00119 * * *$ & $0.00192 * * *$ & $-0.000741 * * *$ & $-0.00170 * * *$ & 0.000115 & \\
\hline Time. Ln (fertiliser) & $-1.78 \mathrm{e}-06$ & $-0.00361 * *$ & 0.00128 & $-0.00369 * *$ & $-0.0104 * *$ & \\
\hline Time. Ln (livestock) & -0.00329 & 0.00924 & -0.00189 & $-0.0374 * *$ & 0.0282 & \\
\hline Time. Ln (labor) & $-0.00712 * * *$ & $-0.0136 * *$ & $0.0175 * * *$ & 0.00669 & 0.00287 & \\
\hline Time. Ln (capital) & $0.0243 * *$ & $-0.0218 * * *$ & $-0.0144 * * *$ & $0.0587 * *$ & -0.0118 & \\
\hline Ln (Feriliser). Ln (livestock) & $-0.0325^{*}$ & 0.0267 & 0.0169 & -0.113 & -0.246 & \\
\hline Ln (Feriliser). Ln (labor) & 0.00742 & -0.0504 & 0.0341 & $0.214 * *$ & -0.164 & \\
\hline Ln (Feriliser). Ln (capital) & 0.0748 & -0.00646 & $-0.115 * * *$ & 0.194 & 0.525 & \\
\hline Ln (Feriliser). Ln (land) & -0.0473 & $0.107 * *$ & $0.0641 * * *$ & $-0.293 * *$ & 0.257 & \\
\hline Ln (Livestock). Ln (labor) & 0.0833 & -0.100 & $-0.639 * * *$ & 0.148 & $0.686 * *$ & \\
\hline Ln (Livestock). Ln (capital) & $-1.367 * *$ & 0.436 & $1.743 * * *$ & $2.175 * *$ & -0.712 & \\
\hline Ln (Livestock). Ln (land) & 0.224 & -0.208 & $-1.045 * * *$ & -0.893 & -0.530 & \\
\hline Ln (Labor). Ln (capital) & $0.972 * *$ & 0.138 & $1.454 * * *$ & -0.170 & -1.167 & \\
\hline Ln (Labor). Ln (land) & -0.0154 & 0.0589 & $0.262 *$ & $-2.493 *$ & -0.545 & \\
\hline Ln (capital). Ln (land) & $1.237^{*}$ & -0.246 & $2.111 * * *$ & 0.415 & $1.285 * *$ & \\
\hline Constant & 16.26 & -5.901 & $-142.1 * * *$ & $81.00 * * *$ & $-129.0^{*}$ & $6.302 * * *$ \\
\hline Lnlikelihood & 338.8396 & 259.7889 & 268.6413 & 152.2725 & 128.4433 & 717.2222 \\
\hline
\end{tabular}




\begin{tabular}{lllllll}
\hline Variables & Central & Southern & West & East & Mena & Metafrontier \\
\hline Sigma2 & 0.0017 & 0.1295 & 0.0246 & 0.0108 & 0.09 & 0.2116 \\
gamma & - & 0.9426 & - & - & 0.8127 & 0.9389 \\
Eta & - & -0.1215 & - & - & 0.0731 & 0.0081 \\
mu & - & - & - & - & 0.0168 & 1.0001 \\
\hline
\end{tabular}

$* * *, * *$ and $*$ denote $1 \%, 5 \%$ and $10 \%$ level of statistical significance.

Table 2 above presents the likelihood maximum estimations of regional frontiers parameters and the metafrontier. Except for the East region, fertilizers are insignificant for all regions whereas the livestock coefficient is only significant for the West region. The labour force coefficient and the cultivated area is significant for the Central, the West and East regions. The capital is significant for all regions except for the Central region and the Mena. These results show a great variability of regions in productions' sensitivity to used inputs.

Table 3. Technological Gap Ratio (TGR) and Technical Efficiencies (TE) for the Group Frontiers and the Metafrontier (TE*).

\begin{tabular}{|c|c|c|c|c|}
\hline Regions & Mean & Std. Dev. & Min & Max \\
\hline \multicolumn{5}{|l|}{ Central } \\
\hline TE & 0.9886 & 0.0031 & 0.9827 & 0.9912 \\
\hline TGR & 0.3511 & 0.0848 & 0.214 & 0.5388 \\
\hline TE* & 0.3473 & 0.0844 & 0.2118 & 0.5339 \\
\hline \multicolumn{5}{|l|}{ East } \\
\hline TE & 0.9358 & 0.0743 & 0.808 & 0.9877 \\
\hline TGR & 0.6873 & 0.2698 & 0.213 & 0.9948 \\
\hline \multicolumn{5}{|l|}{ Mena } \\
\hline TE & 0.993 & 0.0002 & 0.9926 & 0.9933 \\
\hline TGR & 0.3431 & 0.2753 & 0.0589 & 0.8853 \\
\hline TE* & 0.3407 & 0.2734 & 0.0585 & 0.8791 \\
\hline \multicolumn{5}{|l|}{ Southern } \\
\hline $\mathrm{TE}$ & 0.9394 & 0.089 & 0.4679 & 0.9992 \\
\hline TGR & 0.2922 & 0.088 & 0.1412 & 0.5904 \\
\hline \multicolumn{5}{|l|}{ West } \\
\hline TE & 0.8577 & 0.1472 & 0.5824 & 0.9856 \\
\hline TGR & 0.3857 & 0.1383 & 0.1864 & 0.7817 \\
\hline TE* & 0.3278 & 0.1166 & 0.1455 & 0.5639 \\
\hline \multicolumn{5}{|l|}{ Overall } \\
\hline TE & 0.9273 & 0.1126 & 0.4679 & 0.9992 \\
\hline TGR & 0.3879 & 0.2076 & 0.0589 & 0.9948 \\
\hline TE* & 0.3563 & 0.1944 & 0.0585 & 0.9713 \\
\hline
\end{tabular}

Table 3 above presents the TGR averages and type gaps corresponding to the distance between the specific regions technical efficiency (TE) and the mtafrontier (TE*) which will allow us compare countries efficiency between regions. In average, the results show that with a $92.73 \%$ African regions have a high TE close to the regional production frontier. Thus, the Mena and Central regions are the closest two regions to their regional production frontiers with scores of $98.86 \%$ and $99.3 \%$ respectively. These results are however contradictory if we compare regional technical efficiency to the metafrontier. In the Mena region, which has the highest TE with $99.3 \%$, the efficiency value in relationship with the metafrontier is $34.07 \%$ whereas the West region which has the lowest regional efficiency with $85.77 \%$ has a $32.78 \%$ TE. The East region has the highest TE with $63.95 \%$ whereas the Southern region has the lowest value with $26.93 \%$. Yet, for the set of regions we notice that the TE is of $35.63 \%$ which implies that the Southern region has a technological deficit higher than the average of the continent. Besides, for the whole continent, the TE* is inferior to the general efficiency by an average of $57.1 \%$. These results are superior to the ones obtained by Mugera [22] on technical efficiency and confirm the results obtained by Nkamleu and al.
[17] which highlight that African countries are very close to their regional frontiers while they are still under the global industrial production frontier.

This difference between the regional efficiency and the metafrontier is due to the technological gap between regions. TGR estimations show that African regions have an average low score of $38.79 \%$ which varies from $5.89 \%$ to $99.48 \%$ with a $1,17 \%$ annual growth rate on the period 1980-2012. These results are inferior to those obtained by Nkamleu and al., O'Donnell and al. and Huang and al. [17, 5, 12]. In fact, these differences are explained by the models specifications which depend on likelihood tests ratio scores on one hand, and by the TE scores which are inferior to the results obtained by these research works. The East region has the highest TGR with $68.73 \%$ contrarily to the Southern region which has a $29.22 \%$ score. These results indicate that the technologies adopted by the East region are closer to the best technology available for all the countries, however, substantial efficiency gains for Africa might come out from adopting new technologies. Besides, these results show a given technologies homogeneity adopted by regions as the TGR averages vary from $29,22 \%$ to $38.79 \%$ except for the East region. This implies that apart 
from tl
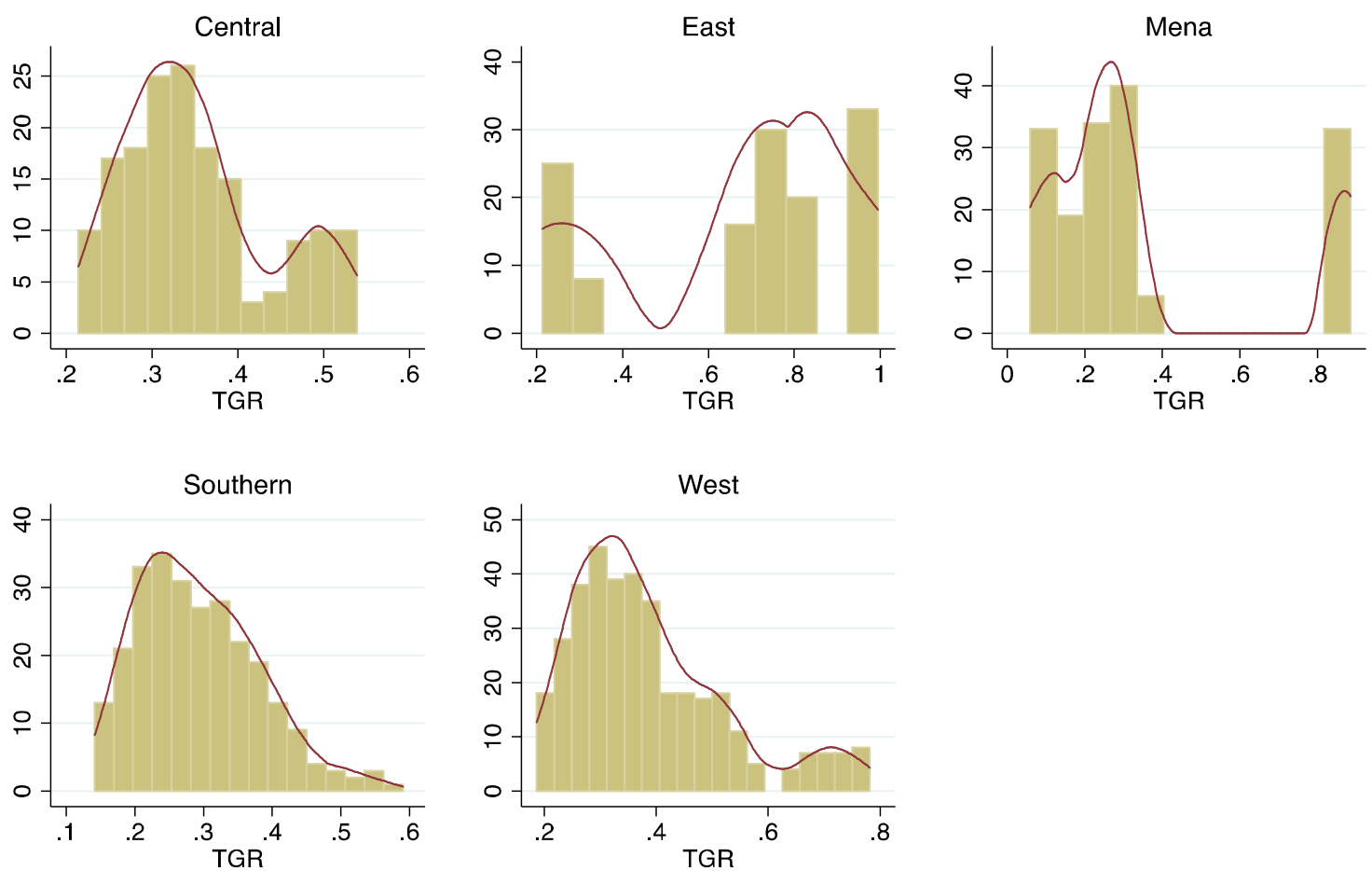

\section{Frequency}

\section{Kernel density}

Figure 1 above shows us frequencies' distribution and the TGR scores density per region. The graphs show us that there is a TGR score heterogeneity per region meaning that there is a strong adopted technologies variability between the countries of a region. For instance. for the Mena regions countries, the TGR fluctuates between $5.89 \%$ and $88.53 \%$, with a type gap of 0.27 . However, this heterogeneity is less observed in the Central region where the TGR fluctuates between 0.21 and 0.53 with a type gap of 0.08 .

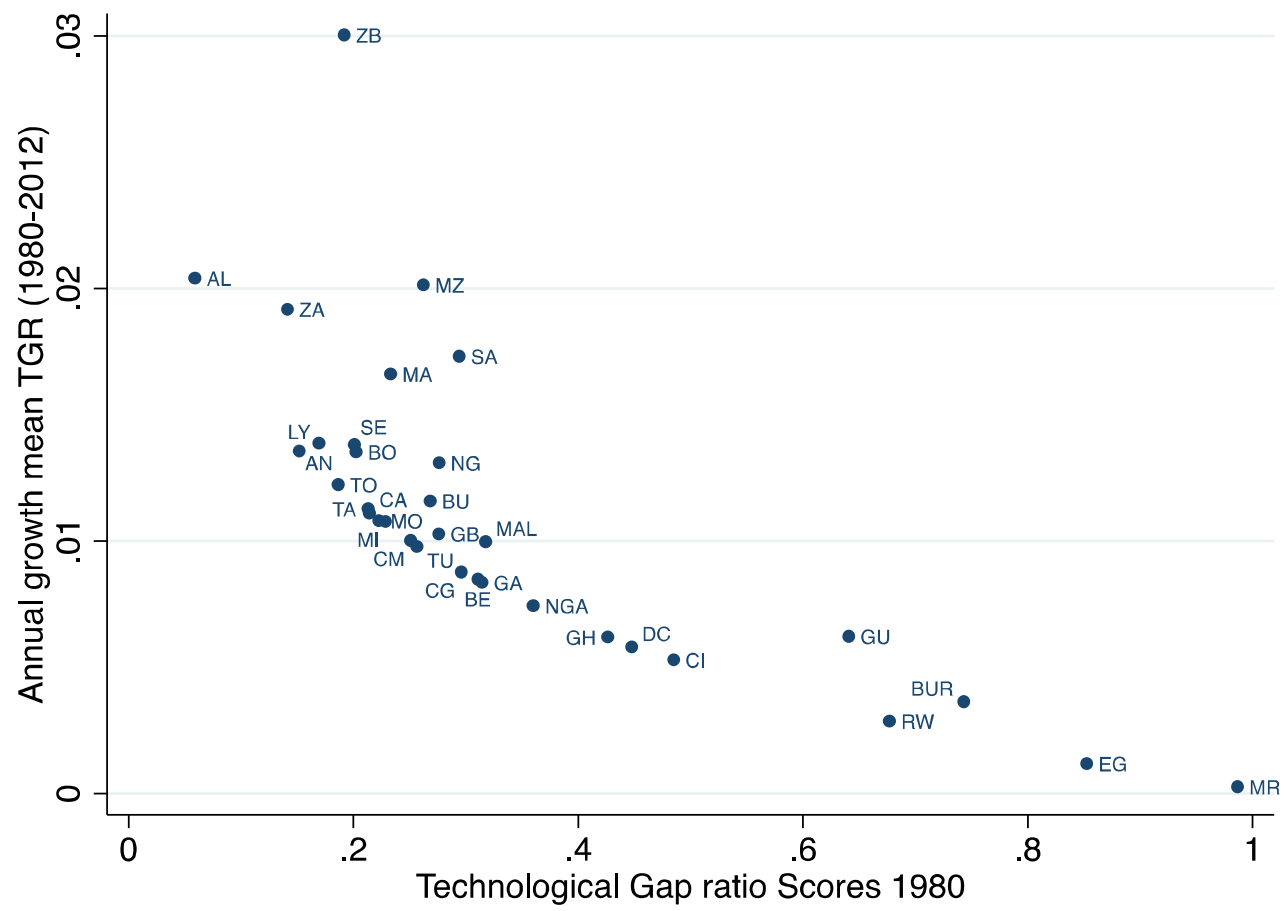

Figure 2. Initial TGRs in 1980 and annual growth mean TGRs overall period (1980-2012) (33 countries*). *See Iable Al for country abbreviations. 
Figure 2 above shows us the yearly average growth rate on the 1980-2012 period relatively to the initial TGR level. This figure shows that the use of the best existing technologies by African countries progresses at a very low speed, the fastest speed is obtained by Zimbabwe which has a TGR average growth rate of $3 \%$. Moreover, we notice that countries which had low initial technology levels have high yearly average growth rate whereas the reverse effect is observed in countries with initial technology levels. For instance, Algeria which had a $5.89 \%$ TGR has a yearly average growth rate of $2.04 \%$. It means that there is a global convergence process in technologies adopted by countries. These results are alike those obtained by Tian [23] who notice a club convergence existence in Africa agricultural production.

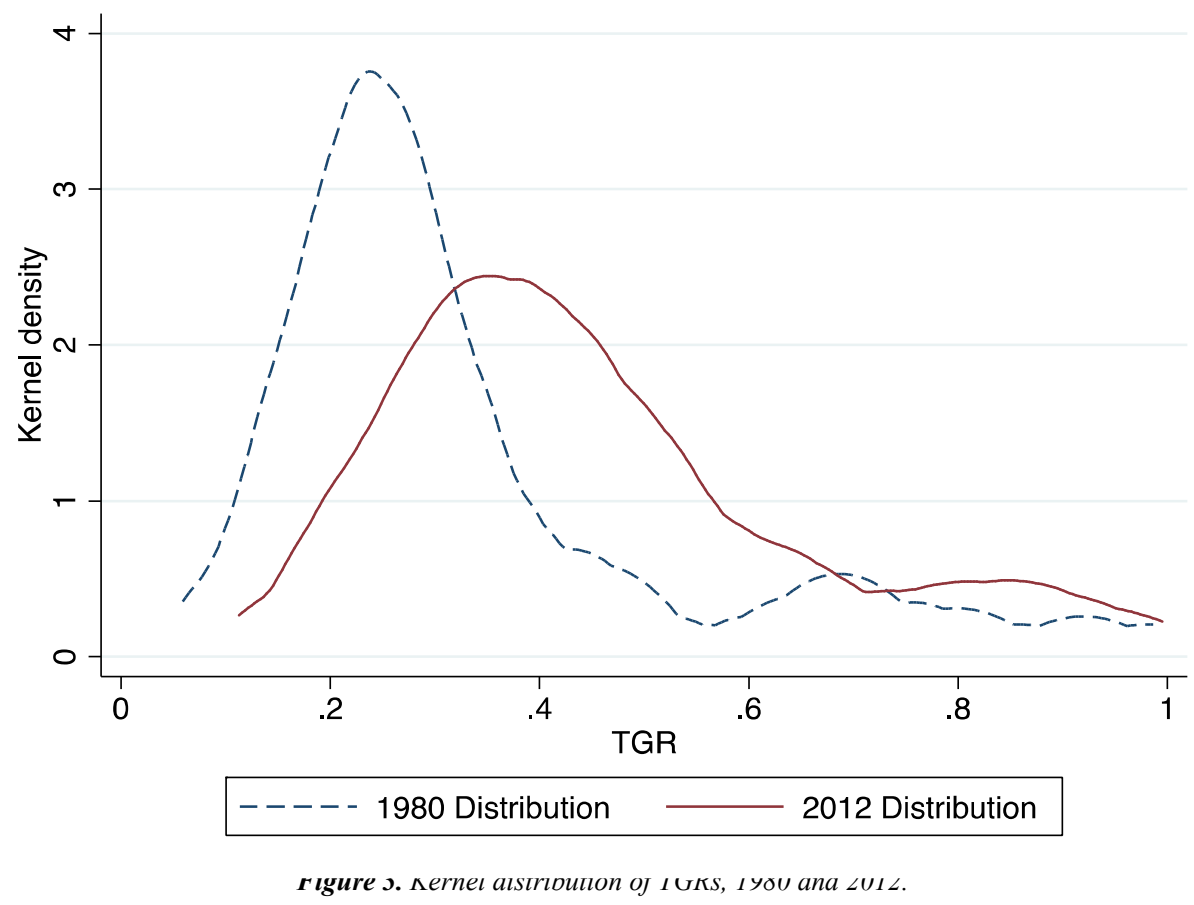

So, to analyse the TGR progress in the time for African countries, we have used the non-parametric distribution to assess the TGR scores distribution between 1980 and 2012 represented by figure 3 . The figure indicates that the TGR distribution is moved to the right meaning that in average, African countries are getting closer to their optimal production frontiers. In other words, a catching-up is noticed between countries with low TGR levels and those with high ones.

However, convergence presence is moderated because most late countries have different yearly average TGR growth rates which confirms the heterogeneity obtained on the regional level. These different results obtained through figures 2 and 3, show us that countries improve their agricultural technologies but at a non-uniform speed from a region to another. Firstly, such differences can be explained by the multiplicity of regional and national agricultural development policies adopted in isolation by countries or regions with divergent strategies. Secondly, they can be linked to the capacity of adapting and imitating available new technologies because capital donations and endogenous capacities to master technological change are different between countries.

\section{Conclusion}

Technologies' adoption plays an important role in different regions' technical efficiency and agricultural productivity improvement. However, in Africa, there still is a production systems' heterogeneity due to technical differences between regions despite programmes installing and common agreements adoption intended to reduce technological gaps. As a matter of fact, this research's objective is to analyse technological differences between the five African regions composed of 33 countries on the period 1980-2012. Differences in technologies between regions are estimated from frontiers specific to each region and the production metafrontier using the stochastic metafrontier approach (SMF) of Huang and al. [12].

In general, the results show in a first time that all the regions make their production closely to the regional frontier and are thus technically efficient. However, this agricultural performance of regions is misleading because regions are closer to their regional frontier than to the continent global frontier. For instance, the Mena region which is the most efficient one with a $99.3 \%$ score gets a $34.07 \%$ score when compared to all other African regions. Secondly, the technical gap ratio for the whole continent is $38.79 \%$ with a $1.17 \%$ very low average growth rate followed by a TGRs heterogeneity in the regions. The East African region is the most competitive one and the closest one to the production metafrontier followed respectively by the West, Central, Mena and Southern regions. Thirdly, on all the period, the results show that countries having low initial technology levels have the 
highest average growth rates on the whole period meaning that a catching-up phenomenon is in action related to the best available technology. Besides, all the results suggest that it is possible to improve agricultural production by changing the production technologies used in regions.

In terms of recommendations, economic policies should be directed to new production technologies' introduction. Thus, it is important for African countries both public and private sectors to make investments in agricultural technology acquisition and to promote technological innovation by supporting Research and Development efforts so as to reduce technological gaps. More precisely, it is up to the Central, Mena, Southern and West regions to install new production systems with higher capital density and technological progress induced by research and innovation in order to catch-up the East region. Moreover, on the continental region, the installing of a programme promoting a larger technologies expansion and of agricultural vulgarization will help technologies and knowledge's transfer to agricultural producers. In other words, public policies should create a continental experience sharing mechanism with the countries or regions with higher productivity levels in order to sustainably reduce technological gaps between regions.

\section{Acknowledgements}

I express my gratitude to Mr. Charles Dossa for his contribution to the improvement of this research work quality.

\section{Appendix}

Table A1. Country abbreviations.

\begin{tabular}{llll}
\hline Angola & AN & Madagascar & MA \\
Algeria & AL & Malawi & MAL \\
Benin & BE & Mali & MI \\
Botswana & BO & Maurice & MR \\
Burkina-Faso & BU & Mozambique & MZ \\
Burundi & BUR & Morrocco & MO \\
Cameroon & CM & Niger & NG \\
Central-African & CA & Nigeria & NGA \\
Congo & CG & Rwanda & RW \\
Cote d'Ivoire & CI & Senegal & SE \\
Democratic Republic of & DC & South Africa & SA \\
Congo & EG & Tanzania & TA \\
Egypt & GA & Togo & TO \\
Gabon & GB & Tunisia & TU \\
Gabon & GH & Zambia & ZA \\
Ghana & GU & Zimbabwe & ZB \\
Guinée & LY & & \\
Lybia & & & \\
\hline
\end{tabular}

\section{References}

[1] Ng'ombe JN. Technical efficiency of smallholder maize production in Zambia: a stochastic meta-frontier approach. Agrekon 2017; 56: 347-365.

[2] Alem H, Lien G, Hardaker JB, and al. Regional differences in technical efficiency and technological gap of Norwegian dairy farms: a stochastic meta-frontier model. Applied Economics 2019; 51: 409-421.

[3] Churchill SA, Inekwe J, Ivanovski K. Convergence of R\&D intensity in OECD countries: evidence since 1870. Empirical Economics. Epub ahead of print 2019. DOI: https://doi.org/10.1007/s00181-019-01628-1.

[4] Fare R, Grosskopf S, Lovell CAK. Production Frontiers. Cambridge University Press, 1994.

[5] O'Donnell CJ, Rao DSP, Battese GE. Metafrontier frameworks for the study of firm-level efficiencies and technology ratios. Empirical Economics 2008; 34: 231-255.

[6] Jovanovic B, Rousseau PL. General Purpose Technologies. In: Handbook of Economic Growth. Elsevier, pp. 1181-1224.

[7] Hayami Y, Ruttan WV. Induced innovation in agricultural development. Staff Papers Series 1971; 71: 47.

[8] Binswanger HP, Ruttan Vernon. Induced innovation : technology, institutions, and development, https://trove.nla.gov.au/version/13094960 (1978, accessed 11 May 2020).

[9] Battese GE, Rao DSP. Technology Gap, Efficiency, and a Stochastic Metafrontier Function. International Journal of Business and Economics 2002; 1: 87-93.

[10] Battese GE, Rao DSP, O'Donnell CJ. A Metafrontier Production Function for Estimation of Technical Efficiencies and Technology Gaps for Firms Operating Under Different Technologies. Journal of Productivity Analysis 2004; 21: 91-103.

[11] Chang B-G, Huang T-H, Kuo C-Y. A comparison of the technical efficiency of accounting firms among the US, China, and Taiwan under the framework of a stochastic metafrontier production function. Journal of Productivity Analysis 2015; 44: 337-349.

[12] Huang CJ, Huang T-H, Liu N-H. A new approach to estimating the metafrontier production function based on a stochastic frontier framework. Journal of Productivity Analysis 2014; 42: 241-254.

[13] Khanal U, Wilson C, Shankar S, and al. Farm performance analysis: Technical efficiencies and technology gaps of Nepalese farmers in different agro-ecological regions. Land Use Policy 2018; 76: 645-653.

[14] Villano R, Bravo-Ureta B, Solís D, and al. Modern Rice Technologies and Productivity in the Philippines: Disentangling Technology from Managerial Gaps. Journal of Agricultural Economics 2015; 66: 129-154.

[15] Moreira VH, Bravo-Ureta BE. Technical efficiency and metatechnology ratios for dairy farms in three southern cone countries: a stochastic meta-frontier model. Journal of Productivity Analysis 2010; 33: 33-45.

[16] Liu J, Li H, Sriboonchitta S, and al. Technical Efficiency Analysis of Top Agriculture Producing Countries in Asia: Zero Inefficiency Meta-Frontier Approach. In: Kreinovich V, Sriboonchitta S (eds) Structural Changes and their Econometric Modeling. Cham: Springer International Publishing, pp. 702-723.

[17] Nkamleu G Blaise, Nyemeck J, Sanogo D. Metafrontier Analysis of Technology Gap and Productivity Difference in African Agriculture. Journal of Agriculture and Food Economics 2006; 1: 111-120. 
[18] World Development Indicators, Washington DC, http://data.worldbank.org/data-catalog/world-development-ind icators. (2020).

[19] Statistic of Food and Agriculture Organization of the United Nations, http://www.fao.org/faostat/en/\#data. (2020).

[20] Battese GE, Coelli TJ. Frontier Production Functions, Technical Efficiency and Panel Data: With Application to Paddy Farmers in India. Journal of Productivity Analysis 1992; 3: $153-169$.

[21] Battese GE, Rao DSP, Walujadi D. Technical Efficiency and
Productivity Potential of Firms Using a Stochastic Metaproduction Frontier. Efficiency Series Paper 2001; 21.

[22] Mugera A, Ojede A. TECHNICAL EFFICIENCY IN AFRICAN AGRICULTURE: IS IT CATCHING UP OR LAGGING BEHIND?: Technical Efficiency in African Agriculture. Journal of International Development 2014; 26 : 779-795.

[23] Tian X, Yu X. Crop yield gap and yield convergence in African countries. Food Security. Epub ahead of print 3 September 2019. DOI: 10.1007/s12571-019-00972-5. 